\title{
Left ventricular systolic function in aortic stenosis
}

\author{
H. P. Krayenbuehl, O. M. Hess, M. Ritter, E. S. Monrad and H. Hoppeler \\ Division of Cardiology, Medical Policlinic, University Hospital, Zürich, Switzerland
}

\begin{abstract}
KEY WORDS: Aortic stenosis, left ventricular ejection fraction, myocardial contractility, afterload mismatch, myocardial morphology.

In aortic valve stenosis, concentric hypertrophy develops which is characterized by a reduced end-diastolic radius-to-wall thickness ratio $(r / h)$ with an essentially normal cavity shape. As long as the product of $(r / h)$ and LV systolic pressure remains constant, hypertrophy is appropriate. An increase in the product, which represents an increase in wall stress signals inadequate $L V$ hypertrophy. Although at first glance, massive $L V$ hypertrophy appears favourable for the maintenance of a normal $L V$ ejection fraction in aortic stenosis, data from 23 studies of the literature have shown an inverse relationship between ejection fraction and $L V$ angiographic mass $m^{-2}(r=-0.59)$. Both a degree of hypertrophy inadequate to keep systolic wall stress within normal limits and a reduction of $L V$ contractility may explain the depression of ejection fraction when $L V$ angiographic mass is sizeably increased. Conversely, a normal ejection fraction in aortic stenosis may not be indicative of normal systolic myocardial function under all circumstances. In the presence of mildly reduced contractility, a normal ejection fraction may be maintained by the use of preload reserve. Assessment of myocardial structure from $L V$ endomyocardial biopsies revealed no differences in muscle fibre diameter, interstitial fibrosis and volume fraction of myofibrils between patients with aortic stenosis having a normal and those with a depressed ejection fraction. Preoperative ejection fraction is a poor predictor of postoperative survival, whereas markedly increased preoperative angiographic mass and end-systolic volume have been reported to predict an unsatisfactory postoperative outcome characterized by either death or poor LV function.
\end{abstract}

\section{Ventricular geometry and its implications for systolic function}

Left ventricular (LV) chronic pressure overload in response to aortic valve stenosis leads to marked hypertrophy of the myocardium characterized by a decrease of end-diastolic radius-to-wall thickness ratio $(r / h)$ with the cavity shape remaining essentially normal. The decrease of $(r / h)$ is the typical feature of concentric hypertrophy. As long as the product of $(r / h)$ and LV systolic pressure remains constant, hypertrophy is appropriate ${ }^{[l]}$. An increase of the product which represents an increase in wall stress signals inadequate LV hypertrophy. The increase of wall thickness at essentially normal cavity dimensions is of importance for the ejection dynamics of the left ventricle. To achieve a normal $\mathrm{LV}$ ejection fraction in concentric hypertrophy, a lower percentage of midwall fibre shortening than in a nonhypertrophied ventricle is required because the contribution of wall thickening to inward wall displacement and hence reduction of cavity size is increased $^{[2-4]}$.

Address for correspondence. H. P Krayenbuehl, MD, Division of Cardiology. Medical Policlinic, University Hospital, CH-809l Zünch, Switzerland.
Systolic function, left ventricular muscle mass and myocardial contractility

Left ventricular systolic function as assessed from ejection fraction is within normal limits in about two-thirds of the patients who are referred for catheterization with a view to aortic valve replacement. In one-third ejection fraction is depressed despite a massive increase of LV angiographic muscle mass which at first glance should be favourable for maintaining ejection fraction within normal limits. In 64 patients with pure aortic stenosis (aortic reflux absent in 22 and aortic regurgitant fraction $<0.20$ in 42 ) but without coronary artery disease, we found an inverse relationship between biplane ejection fraction and left ventricular angiographic muscle mass index (LMMI), $(r=-0 \cdot 47$, $P<0.001)$. Similarly, 30 mean values of ejection fraction and LMMI taken from 23 studies of the literature $\mathrm{e}^{[5-12.14-18.20-27.29-31]}$ (Table 1), yielded a significant inverse correlation, as depicted in Fig. 1. Ejection fraction was also inversely correlated with LV end-diastolic pressure (Table 1).

The reason why ejection fraction is depressed in aortic stenosis despite massive increase of angiographic mass has been a matter of debate. Gunther 
Table I Regression unaly'ses in aortic stenosis hased on data (mean values) taken from the literature

\begin{tabular}{lllrl}
\hline & $n$ & $P$ & $r$ & \multicolumn{1}{c}{ References } \\
\hline EF vis. LMMI & 30 & 0.001 & -0.589 & $6-12,14-18,20-27,29-31$ \\
EDVI is. LMMI & 30 & 0001 & 0608 & $6-12,14-18,20-27,29-31$ \\
ESVI ws LMMI & 30 & 0.001 & 0657 & $6-12,14-18,20-27,29-31$ \\
LVEDP vs. LMMI & 25 & 0.02 & 0.487 & $6,9-12,14-18,20,22-27,29,31$ \\
EF vs. LVEDP & 30 & 0.001 & -0.719 & $5,6,9-20,22-29,31$ \\
\hline
\end{tabular}

EF, left ventricular ejection fraction (\%); LMMI, left ventricular angiographıc mass index $\left(\mathrm{g} \mathrm{m}^{-2}\right)$; EDVI, left ventricular end-diastolic volume index $\left(\mathrm{ml} \mathrm{m} \mathrm{m}^{-2}\right)$; ESVI, left ventricular end-systolsc volume index $\left(\mathrm{ml} \mathrm{m} \mathrm{m}^{-2}\right)$; LVEDP, left ventncular end-diastolic pressure $(\mathrm{mmHg}): n$. number of observations; $P$, probability (least-square regression analysis); $r$, correlation coefficient.

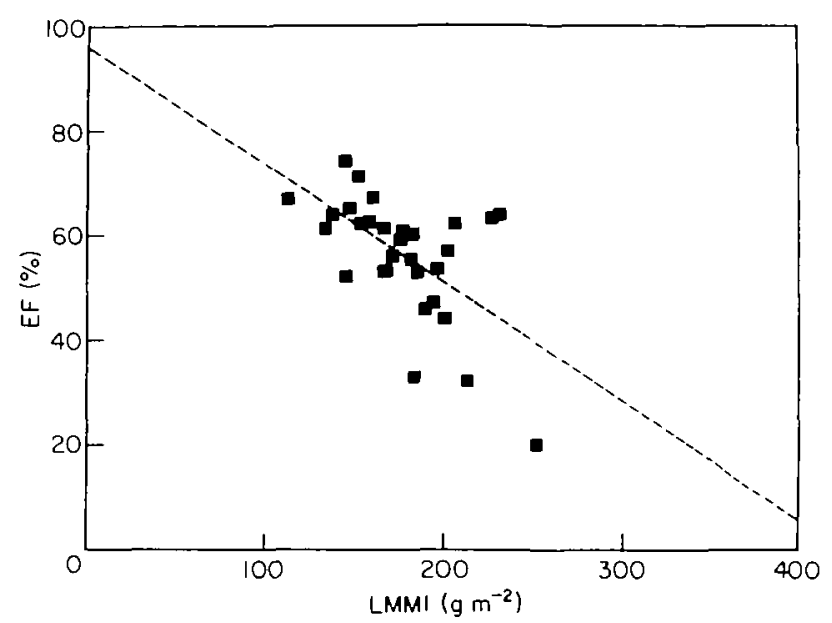

Figure / Relationshıp between left ventricular ejectıon fraction (EF) and left ventricular angiographic muscle mass index (LMMI) derıved from published mean values. There is a significant inverse correlation. The dashed line is the calculated regression line. $r=-0.59, n=30$, $P<0.001$

and Grossman ${ }^{[17]}$ have considered excess afterload due to inadequate hypertrophy of normally functioning cardiac muscle to be at the origin of impaired left ventricular shortening. They described an excellent $(r=-0.96)$ inverse relationship between ejection fraction and mean systolic wall stress in 14 patients with aortic stenosis. However, more recent studies have shown that in aortic stenosis at similar peak systolic circumferential wall stress, either normal or increased, patients with depressed isovolumic contractile indexes have a significantly lower ejection fraction than do those with normal isovolumic contractility ${ }^{25]}$ and that in the diagram correlating ejection fraction to peak systolic or endsystolic wall stress the values of many patients fall down and to the left of the normal range ${ }^{[28.31 .32]}$. Thus, although afterload mismatch may adversely affect $L V$ ejection fraction, depression of contractılity associated with advanced LV hypertrophy appears to be the major determinant of LV pump dysfunction in aortic stenosis. Another argument that afterload mismatch is not the main reason for depressed ejection fraction comes from observations early after reduction or removal of $\mathrm{LV}$ 


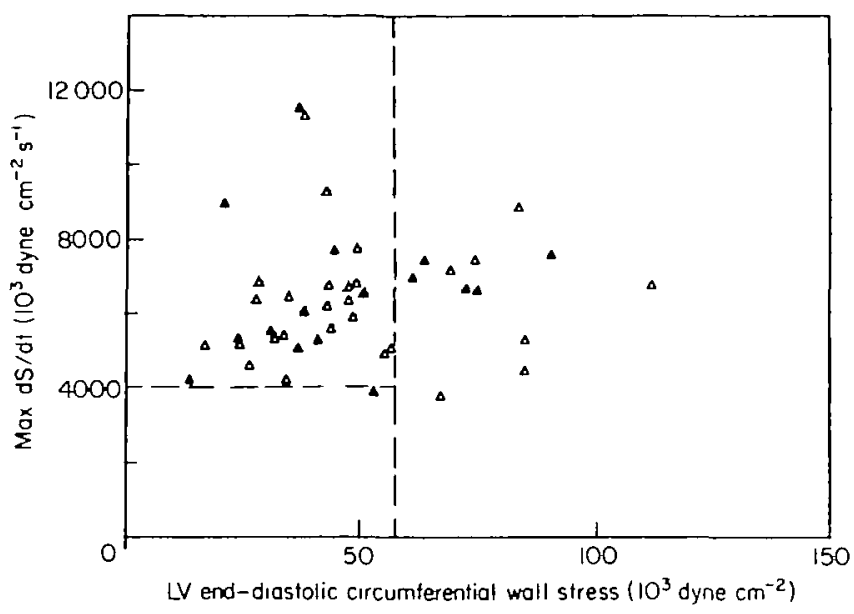

Figure 2 Relationship between maximal rate of rise of left ventricular circumferential wall stress ( $\max \mathrm{dS} / \mathrm{dt}$ ) and left ventricular end-diastolic crcumferential wall stress in 44 patients with aortic stenosis (AS) and an ejection fraction $(E F) \geqslant 57 \%$. The shaded area encompasses the values found in 23 controls. Thus the upper left quadrant defines the normal relationship between max $\mathrm{dS} / \mathrm{dt}$ and end-diastolic stress In 12 patients the relationship was shifted to the right. Hence left ventricular myocardial contractulity appeared to be mildly depressed in these pattents. Mobilizatıon of preload reserve allowed maintenance of ejection fractıon withın normal limits

pressure burden. After aortic balloon valvuloplasty in patients with ejection fraction $\leqslant 55 \%$ McKay et al. ${ }^{[33]}$ reported only a modest immediate increase of ejection fraction from 40 to $46 \%$ and in patients with aortic stenosis and depressed ejection fraction (mean preoperative ejection fraction $33 \%$ ) Schwarz et al. $^{[34]}$ have found an increase to $43 \% 17$ days after valve replacement, whereas nine months after surgery ejection fraction had finally increased to $71 \%$.

A LV ejection fraction within the limits of ejection fractions obtained in control subjects is generally considered to be indicative of a normal LV contractility in patients with aortic stenosis except in situations where afterload is below normal as in patients with congenital aortic stenosis who show supranormal LV shortening ${ }^{[35]}$. Moreover, in evaluating the meaning of a normal ejection fraction in aortic stenosis it has to be taken into account that the magnitude of ejection fraction is also influenced by preload.

To analyse further LV contractility in our 44 patients with a normal ejection fraction, we have assessed the relationship between maximal rate of rise of circumferential wall stress $(\max \mathrm{dS} / \mathrm{dt})$ and end-diastolic stress $\left(S_{c d}\right)^{[36]}$. Thirteen patients had an abnormal relationship in this isovolumic function diagram (Fig. 2) whereby in 12 preload, as assessed by $S_{e d}$, was increased. Thus in the presence of mildly reduced contractility, a normal ejection fraction may be maintained by the use of preload reserve.

\section{Systolic function and myocardial structure}

Myocardial structure was assessed from LV endomyocardial biopsies in the same 64 patients with aortic stenosis mentioned above. Muscle fibre diameter and interstitial fibrosis (IF) in 44 patients with normal ejection fraction did not differ from the corresponding values in 20 patients with depressed ejection fraction. LV fibrous content (FC) was $29.6 \mathrm{~g} \mathrm{~m}^{-2}$ in those with normal and $37.9 \mathrm{~g} \mathrm{~m}^{-2}$ $(P<0.025)$ in those with depressed ejection fraction. This difference was mainly due to the fact that LMMI which enters the formula for calculation of FC (IF $\times \mathrm{LMMI} / 100)$ was higher $(P<0.001)$ in those with depressed $\left(199 \mathrm{~g} \mathrm{~m}^{-2}\right)$ than in those with preserved ejection fraction $\left(158 \mathrm{~g} \mathrm{~m}^{-2}\right)$. The volume 
fraction of myofibrils (VFM) did not differ in patients with depressed and normal ejection fraction. This observation is at variance with the results of Schwarz et al. ${ }^{[24]}$ who found VFM to be significantly reduced in patients with aortic stenosis and an ejection fraction $<55 \%$.

\section{Systolic function and prognosis after aortic valve replacement}

In patients with aortic stenosis or combined aortic valve lesions and an ejection fraction $<50 \%$, more early deaths in the first month after aortic valve replacement have been reported than in patients with an ejection fraction $\geqslant 50 \%{ }^{[37]}$. However, the difference was not significant. Subsequent longterm survival was not affected by the preoperative ejection fraction. Other studies ${ }^{[19,30.32 .38-40]}$ have also found no relationship between preoperative ejection fraction and long-term survival. This lack of relationship appears to stem from the fact that postoperative death due to myocardial dysfunction is uncommon and most deaths are related to prosthetic valve complications or co-existent coronary artery disease ${ }^{[38]}$. When surgical outcome was assessed by both postoperative death and inadequate restoration of $\mathrm{LV}$ function, preoperative angiographic muscle mass inde ${ }^{[30]}$ and end-systolic volume index ${ }^{[32]}$ were found to be preoperative predictors of an unsatisfactory postoperative outcome.

This work was supported by a grant from the Swiss National Science Foundation.

\section{References}

[1] Gaasch WH. Left ventricular radius to wall thickness ratio. Am J Cardiol 1979; 43: 1189-94.

[2] Dodge HT, Frimer M, Stewart DK. Functional evaluation of the hypertrophied heart in man. Circulation Res 1974; 35 (Suppl II): 122-7.

[3] Kreuzer $H$, Neuhaus KL. Invasive Untersuchungsmethoden zur Erfassung einer gestōrten Kontraktilıtät. Verh Dtsch Ges Kreislaufforschg 1976; 42: 31-9.

[4] Krayenbuehl HP, Hess OM, Hirzel HO. Pathophys1ology of the hypertrophied heart in man. Eur Heart J 1982; 3 (Suppl A): 125-31

[5] Bunnell IL, Grant C, Greene DG Left ventricular function derived from the pressure-volume diagram. Am J Med 1965; 39: 881-94

[6] Kennedy JW, Twiss RD, Blackmon JR, Dodge HT. Quantıtative angiocardiography. III. Relatıonships of left ventricular pressure, volume and mass in aortic valve disease. Circulation 1968; 38: 838-45.

[7] Dodge HT, Baxley WA. Left ventricular volume and mass and their significance in heart disease. Am J Cardiol 1969; 23: 528-37.
[8] Gould KL, Kennedy JW, Frimer M, Pollack GH, Dodge HT. Analysis of wall dynamics and directional components of left ventricular contraction in man. Am J Cardiol 1976, 38: 322-31.

[9] Trenouth RS, Phelps NC, Neill WA. Determinants of left ventricular hypertrophy and oxygen supply in chronic aortic valve disease. Circulation 1976; 53: 644-50.

[10] Kennedy JW, Doces J, Stewart DK. Left ventricular function before and following aortic valve replacement. Circulation 1977; 56. 944-50.

[11] Johnson LL, Sciacca RR, Ellis K, Weiss M B, Cannon PJ. Reduced left ventricular myocardial blood flow per unit mass in aortic stenosis Circulation 1978; 57: 582-90.

[12] Peterson KL, Tsuji J, Johnson A, D 1 Donna J, LeW 1 inter M. Diastolic left ventricular pressure-volume and stress-strain relations in patients with valvular aortic stenosis and left ventricular hypertrophy. Circulation 1978; 58: 77-89.

[13] Smith N, McAnulty JH, Rahimtoola SH Severe aortic stenosis with impaired left ventricular function and clinical heart failure: results of valve replacement. Circulation 1978; 58: 255-64.

[14] Pantely G, Morton M, Rahimtoola SH. Effects of successful, uncomplicated valve replacement on ventricular hypertrophy, volume and performance in aortic stenosis and incompetence. J Thorac Cardiovasc Surg 1978; 75 : 383-91

[15] Schwarz F, Flameng W, Thormann J, Ensslen M, Sesto $\mathbf{M}$, Schlepper $\mathbf{M}$. Cardiac reserve during isoproterenol stress in patients with aortic valve disease before and after corrective surgery. Am Heart J 1978, 95: 146-53

[16] Krayenbuehl HP, Turina $M$, Hess OM, Rothlın ME, Senning $\AA$ Pre- and post-operative left ventricular contractile function in patients with aortic valve disease. $\mathrm{Br}$ Heart J 1979; 41: 204-13.

[17] Gunther S, Grossman W. Determinants of ventricular function in pressure-overload hypertrophy in man. Circulation 1979, 59: 679-88.

[18] Schwarz F, Flameng W, Langebartels F, Sesto $M$, Walter $P$, Schlepper M. Impaired left ventricular function in chronic aortic valve disease: survival and function after replacement by Björk-Shiley prosthesis. Circulation 1979; 60: 48-58.

[19] Thompson R, Yacoub M, Ahmed M, Seabra-Gomes R, Rickards A, Towers M. Influence of preoperative left ventricular function on results of homograft replacement of the aortic valve for aortic stenosis Am J Cardiol 1979; 43. 929-38.

[20] Fifer MA, Gunther S, Grossman W, Mirsky I, Carabello B, Barry WH. Myocardial contractile function in aortic stenosis as determined from the rate of stress development during isovolumic systole. Am J Cardiol 1979; 44: $1318-25$

[21] Strauer BE. Myocardial oxygen consumption in chronic heart disease. role of wall stress, hypertrophy and coronary reserve. Am J Cardiol 1979; 44: 730-40.

[22] Carabello BA, Green LH, Grossman W, Cohn LH, Koster JK, Collins JJ. Haemodynamic determinants of prognosis of aortic stenosis and advanced congestive heart failure. Circulation 1980; 62: 42-8.

[23] Spann JF, Bove AA, Natarajan G, Kreulen T Ventricular performance and compensatory mechanisms in patients with aortic stenosis. Circulation 1980; 62: 576-82. 
[24] Schwarz F, Schaper J, Kittstein D, Flameng W, Walter P, Schaper W Reduced volume fraction of myofibrils in myocardium of patients with decompensated pressure overload. Circulation 1981; 63: 1299-1304.

[25] Huber D, Grimm J, Koch R, Krayenbuehl HP. Determinants of ejection performance in aortic stenosis. Circulation 1981; 64: 126-34.

[26] Eichhorn P, Grimm J, Koch R, Hess O, Carroll J, Krayenbuehl HP. Left ventricular relaxation in patients with left ventricular hypertrophy secondary to aortic valve disease. Circulation 1982; 65: 1395-404.

[27] Niemelā K, Ikäheimom, Takkunen J. Functional evaluation after aortic valve replacement. Scand J Thor Cardiovasc Surg 1983; 17: 221-5.

[28] De Pace NL, Ren JF, Iskandrian AS, Kotler MN, Hakki AH, Segal BL. Correlation of echocardiographic wall stress and function in aortic stenosis. Circulation 1983; 67. 854-9.

[29] Mehmel HC, Schwarz F, Ruffmann K, Manthey J, von Olshausen K, Kübler W. End-systolic pressure-volume and end-systolic stress-volume relationships in patients with aortic stenosis and with normal valvular function. Basic Res Cardiol 1983; 78: 338-50.

[30] Saoud 1 NC, Berland J, Senant J, et al. Rétrécissement aortique à fraction d'éjéctıon préopératoire basse. Arch Mal Coeur 1985; 78. 1399-1407.

[31] Wisenbaugh T, Booth D, de Maria A, Nissen S, Walters J. Relationship of contractile state to ejection performance in patients with chronic aortic valve disease. Circulation 1986; 73: 47-53.

[32] Carabello BA, Willams H, Gash AK, et al. Hemodynamic predictors of outcome in patients undergoing valve replacement. Circulation 1986; 74 : 1309-16.
[33] McKay RJ, Safian RD, Lock JE, et al. Assessment of left ventricular and aortic valve function after aortic balloon valvuloplasty in adult patients with critical aortic stenosis. Circulation 1987; 75: 192-203.

[34] Schwarz F, Ehrmann J, Olschewski P, Scheurlen H, Saggan W, Kübler W. Patients with significant aortic incompetence should not be operated on unul they are symptomatic. Z Kardiol 1986; 75 (Suppl 2): 133-6.

[35] Borow KM, Colan SD, Neumann A. Altered left ventricular mechanics in patients with valvular aortic stenosis and coarctation of the aorta: effects on systolic performance and late outcome. Circulation 1985; 72 : 515-22.

[36] Krayenbuehl HP, Hess OM, Schneider J, Turina M Physiologic or pathologic hypertrophy. Eur Heart J 1983; 4 (Suppl A): 29-34.

[37] OToole JD, Geiser EA, Reddy PS, Curtuss EI, Landfaur RM. Effect of preoperative ejection fraction on survival and hemodynamic improvement following aortic valve replacement. Circulation 1978; 58: 1175-84.

[38] Henry WL, Bonow RO, Borer JS, et al. Evaluation of aortic valve replacement in patients with valvular aortic stenosis. Circulation 1980; 61: 814-25.

[39] Forman R, Firth BG, Barnard MS. Prognostic sıgnificance of preoperative left ventricular ejection fraction and valve lesion in patients with aortic valve replacement. Am J Cardiol 1980; 45: 1120-25.

[40] Schwarz F, Ruffmann K, Olschweski M, et al. The effect of impaired left ventricular function on the prognosis after isolated aortic valve replacement. Z Kardiol 1986 , 75: $516-21$ 